\title{
Parkin depletion delays motor decline dose-dependently without overtly affecting neuropathology in a-synuclein transgenic mice
}

\author{
Margot Fournier ${ }^{1,4,9 \dagger}$, Amandine Roux ${ }^{1,2,3 \dagger}$, Jérôme Garrigue ${ }^{1,2,3}$, Marie-Paule Muriel ${ }^{1,2,3}$, Paul Blanche ${ }^{5}$, \\ Hilal A Lashuel ${ }^{4}$, John P Anderson ${ }^{6}$, Robin Barbour ${ }^{6}$, Jiping Huang ${ }^{6}$, Sophie Tezenas du Montcel ${ }^{5,7}$, \\ Alexis Brice ${ }^{1,2,3,8}$ and Olga Corti $1^{1,2,3^{*}}$
}

\begin{abstract}
Background: Mutations of the gene encoding the major component of Lewy bodies (LB), a-synuclein (a-syn), cause autosomal dominant forms of Parkinson's disease (PD), whereas loss-of-function mutations of the gene encoding the multifunctional E3 ubiquitin-protein ligase Parkin account for autosomal recessive forms of the disease. Parkin overproduction protects against a-syn-dependent neurodegeneration in various in vitro and in vivo models, but it remains unclear whether this process is affected by Parkin deficiency. We addressed this issue, by carrying out more detailed analyses of transgenic mice overproducing the A30P variant of human a-syn (hA30Pa-syn) and with two, one or no parkin knockout alleles.
\end{abstract}

Results: Longitudinal behavioral follow-up of these mice indicated that Parkin depletion delayed diseasepredictive sensorimotor impairment due to a-syn accumulation, in a dose-dependent fashion. At the end stage of the disease, neuronal deposits containing fibrillar a-syn species phosphorylated at S129 ( $P^{S 129}$ a-syn) were the predominant neuropathological feature in hA30Pa-syn mice, regardless of their parkin expression. Some of these deposits colocalized with the LB markers ubiquitin and a-syn truncated at D135 (a-synD135), indicating that $\mathrm{P}^{5129} \mathrm{a}$-syn is subjected to secondary posttranslational modification (PTM); these features were not significantly affected by parkin dysfunction.

Conclusions: These findings suggest that Parkin deficiency acts as a protective modifier in a-syn-dependent neurodegeneration, without overtly affecting the composition and characteristics of a-syn deposits in end-stage disease.

Keywords: a-syn phosphorylation, a-syn truncation, Ubiquitin, Posttranslational modifications, Transgenic mice overproducing a-syn, parkin knockout mice, Parkinson's disease

\section{Background}

Biochemical studies of $\alpha$-syn within Lewy bodies (LB) revealed various posttranslational modifications (PTM) of the protein, some of which are associated with Parkinson's disease (PD) and other synucleinopathies (for a recent review on $\alpha$-syn PTM, see [1]). The most abundant $\alpha$-syn PTM is phosphorylation: nearly $90 \%$ of the molecules of this protein in LB are phosphorylated at $\mathrm{S} 129\left(\mathrm{P}^{\mathrm{S} 129} \alpha\right.$-syn) $[2,3]$. $\alpha$-Syn is also ubiquitylated [2,4-6]; various lysine residues affected by this PTM have been identified, mostly in

\footnotetext{
*Correspondence: olga.corti@upmc.fr

'Equal contributors

'Inserm, U 975, CRICM, Hôpital de la Pitié-Salpêtrière, F-75013 Paris, France

2UPMC Université Paris 06, UMR_S975, F-75013, Paris, France

Full list of author information is available at the end of the article
}

the $\mathrm{N}$-terminal part of the protein $[2,7,8]$. Ubiquitin has been shown to be primarily associated with $\mathrm{P}^{\mathrm{S} 129} \alpha$-syn $[2,4,5]$, raising the possibility of crosstalk between the two modifications. In addition, about $15 \%$ of $\alpha$-syn is truncated in LB $[9,10]$ and various C-terminally cleaved $\alpha$-syn species (e.g. D135, Y133, N122, D119, D115) have been identified [2,4,9-12]. All these $\alpha$-syn species have been shown to accumulate in animal models of $\alpha$ synucleinopathy $[11,13-24]$, but they have mostly been studied independently of each other. Thus, the interplay between them remains poorly understood.

Most early-onset autosomal recessive cases of PD are due to mutations in the gene encoding Parkin [25,26], an E3 ubiquitin-protein ligase involved in the ubiquitylation

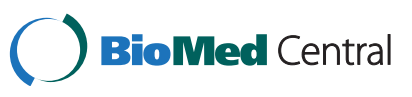


of a number of substrates (e.g. CDCRel-1, Pael R, synphilin, p38/JTV1/AIMP2, Eps15) and in various cellular mechanisms, including signaling pathways, synaptic transmission, proteasomal protein degradation and the autophagy of dysfunctional mitochondria [25,27]. It is unclear whether mutations in the $\alpha$-syn and parkin genes converge into common neuropathological pathways. The overproduction of Parkin protects against $\alpha$-syn-induced toxicity, both in vitro and in vivo [19,28-30], but conflicting results have been reported in models of Parkin depletion, which mimics the loss of protein function underlying PD due to parkin mutations [16,31].

We explored this issue further, in mice producing the pathogenic human A30P variant of $\alpha$-syn (hA30P $\alpha$-syn). Transgenic hA30P $\alpha$-syn mice are a well described model of $\alpha$-synucleinopathy, characterized by an age-dependent lethal movement disorder associated with the deposition of proteinase K-resistant $\alpha$-syn, $\mathrm{P}^{\mathrm{S} 129} \alpha$-syn and ubiquitin throughout the central nervous system [16,21,32]. We previously reported that Parkin deficiency due to biallelic gene knockout delays the onset of the neurodegenerative phenotype in this model [16]. In this study, we used a set of behavioral tests to monitor the development of motor dysfunction in hA30P $\alpha$-syn mice with two, one or no functional parkin alleles. We also provide a detailed immunohistochemical description of the $\alpha$-syn deposits, to clarify the relationships between the various PTM of the protein and the effects of an absence of Parkin. We report that dysfunctional parkin alleles delay the onset of disease signs, in a dose-dependent manner, in hA30P $\alpha$-syn mice, with only modest effects on neuropathological characteristics in end-stage disease.

\section{Methods}

\section{Ethics statement}

All experiments involving mice were approved by the Ile-de-France Regional Ethics Committee for Animal Experiments, Nu3 (P3/2006/006). Post-mortem samples of PD patients were obtained from brains collected in a Brain Donation Program of the Brain Bank "GIE NeuroCEB", run by a consortium of Patient Associations: ARSEP (association for research on multiple sclerosis), CSC (cerebellar ataxias), France Alzheimer and France Parkinson. Consents were signed by the patients or their next of kin in their name, in accordance with French bioethics law. The approval for the collection of samples in the Brain Bank has been granted by the Ministry of Higher Education and Research (authorization \#AC 2007-5).

\section{Behavioral analyses}

Experimental groups of female littermate mice were generated, genotyped and housed, as previously described [16]. In brief, homozygous parkin knockout mice [33] brought into the $\mathrm{C} 57 \mathrm{Bl} / 6 \mathrm{j}$ genetic background by an accelerated backcross procedure were bred with homozygous hA30P $\alpha$ syn mice brought into a $\mathrm{C} 57 \mathrm{Bl} / 6 \mathrm{j}$ background by eight consecutive backcrosses [21]. Mice of the double-heterozygous generation were then crossed to generate littermates of the nine expected genotypes. Age-matched littermates of the genotypes of interest were used for all subsequent analyses. Behavioral studies were performed in the mornings of two consecutive days, by investigators blind to genotype. The animals were weighed, and behavioral tasks were performed in the following order: 1) extension reflex, 2) rotarod test and 3) footprint test. The symmetry of the hindlimb extension reflex and the time spent on a rotating rod were studied as previously described [16]. The amplitude of the extension reflex was characterized as follows: 5swift and wide, 4- normal, 3- mild, 2- narrow, 1- little movement 0 - no extension. On this scale, 3 was considered to correspond to an abnormally low score, because it was not observed in control groups; a score of 2 or 1 was invariably accompanied by an abnormal gait. For the footprint test, the hindpaws and forepaws were inked with different colors and the animal was placed at the entrance of a corridor (10 cm long x $5 \mathrm{~cm}$ wide x $5 \mathrm{~cm}$ high) covered with a paper sheet; the mouse was allowed to walk through without pause. Based on consecutive imprints, we measured the length and width of four steps for the forelimbs and hindlimbs.

\section{Qualitative and quantitative immunofluorescence analyses}

Three cases of sporadic PD and an age-matched control without neurological lesions were selected from the Escourolle Neuropathology Laboratory of Pitié-Salpêtrière Hospital. The PD cases were characterized histopathologically for neuron loss from the substantia nigra and for the presence of LB, as previously described [34]. All histological immunofluorescence staining was performed as described by Vitte et al. [34], after bleaching to eliminate the autofluorescence of the human tissue, by incubating the sections in phosphate-buffered saline (PBS) for $2 \mathrm{~h}$ under the light of a desk lamp at $4^{\circ} \mathrm{C}$. All immunohistochemical analyses in animals were performed in homozygous hA30P $\alpha$-syn+/+ mice with (parkin-/-) or without Parkin deficiency. Animals were killed in the end stage of the disease, about three weeks after the onset of symptoms, and the brain was removed and processed for immunohistochemistry, as previously described [16]. For preabsorption experiments, an antibody directed against $\alpha$-syn truncated at D135 ( $\alpha$-synD135) was first incubated for $6 \mathrm{~h}$ in PBS supplemented with $4 \%$ bovine serum albumin (BSA), 10\% newborn goat serum (NGS) with the recombinant proteins of interest $(\alpha$-synD135, $\alpha$-synY133 and $\alpha$-syn), at an antibody:protein ratio of $1: 2000$. The proportion of LB detected by $\mathrm{P}^{\mathrm{S} 129} \alpha$-syn staining also displaying $\alpha$-synD135 labeling was estimated on 50 LB from the three cases of PD. The percentage of cell bodies and 
processes costained for the different markers was quantified in two or three representative $5 \mu \mathrm{m}$-thick coronal brainstem sections selected on the basis of staining abundance and observed with an epifluorescence microscope (magnification x63, Axioplan 2, Zeiss, Germany). We scored about 50 neuronal cell bodies and 100 processes, identified on the basis of morphology and DAPI staining, for each animal, and six to ten animals from each genotype were analyzed. Brightfield images were acquired with a multipurpose zoom microscope (NIKON AZ100) and NIS software. Colocalization of different types of immunofluorescent labeling was further analyzed with a confocal microscope (Leica SP2 AOBS, Wetzlar, Germany) and a x63 objective. Z-stack images, with $0.2 \mu \mathrm{m} Z$-intervals covering entire immunostained volumes within individual cell bodies or processes $(n=6$ structures), were taken from representative animals $(n=3)$ for each relevant genotype. The degree of colocalization was determined by calculating Pearson's coefficient with the JACoP plug-in of ImageJ software.

\section{Immunostaining for electron microscopy}

Mice were anesthetized with pentobarbital $(130 \mathrm{mg} / \mathrm{kg}$, i.p.; Sigma, St Quentin, France) and perfused transcardially with $4 \%$ PFA freshly prepared in PBS supplemented with $0.01 \%$ glutaraldehyde. Brains were removed and post-fixed by incubation overnight in 4\% PFA. Sections from the brainstem ( $45 \mu \mathrm{m}$ thick), which has been show to contain abundant $\mathrm{P}^{\mathrm{S} 129} \alpha$-syn deposits, were obtained with a vibratome (HM $650 \mathrm{~V}$ Microm International), immunolabeled for $\mathrm{P}^{\mathrm{S} 129} \alpha$-syn and then incubated with 3,3'-diaminobenzidine (DAB) or gold [35]. Ultrathin sections $(60 \mathrm{~nm})$ were analyzed with a JEOL 1200EX II electron microscope at $80 \mathrm{kV}$ (Akishima, Japan).

\section{Antibodies}

Mouse monoclonal anti- $\alpha$-synD135 and anti- $\alpha$-synY133 antibodies were generated essentially as previously described [2], with the peptides CGGEEGYQD and CGGPSEEGY, the corresponding synuclein sequences with three-residue extensions at the $\mathrm{N}$-terminal end for coupling, as immunogens. These peptides were coupled to sheep antimouse IgG (Jackson ImmunoResearch Laboratories, West Grove, PA) with sulfo-EMCS (Molecular Biosciences, Boulder CO). Sera were then purified with Protein A-Sepharose and the antibodies were used at dilutions of 1:1000 (anti- $\alpha$ synD135) or 1:700 (anti- $\alpha$-synY133). We also used the following commercially available primary antibodies: rabbit polyclonal anti-ubiquitin (1:1000) from DAKO, rabbit monoclonal anti- $\mathrm{P}^{\mathrm{S} 129} \alpha$-syn (1:2500 for electron microscopy, otherwise 1:5000) from Abcam; mouse monoclonal anti$\mathrm{P}^{\mathrm{S} 129} \alpha$-syn (1:5000, WAKO); and rabbit polyclonal anti-full length $\alpha$-syn (1:1000) from Affinity Biologicals. For immunohistochemistry, we used the following secondary antibodies: goat anti-rabbit or anti-mouse IgG conjugated to Alexa Fluor 488 (1:1000, Invitrogen), donkey anti-rabbit or antimouse IgG conjugated to Cy3 (1:500, Jackson).

\section{Mass spectrometry analysis (MS)}

Sodium dodecyl sulfate (SDS)-soluble brain fractions [16] were run on an SDS polyacrylamide (15\%) gel, which was then stained with Coomassie blue. Gel pieces containing the proteins of interest were destained and desiccated by incubation twice, for $20 \mathrm{~min}$ each, in 200 $\mu \mathrm{l}$ of $50 \mathrm{mM}$ ammonium bicarbonate, $50 \%$ ethanol. Samples were then dried, incubated with modified trypsin $(12.5 \mathrm{ng} / \mu \mathrm{l})$ overnight at $37^{\circ} \mathrm{C}$ and stored at $-80^{\circ} \mathrm{C}$. The digested peptides were resuspended in $20 \mu \mathrm{l}$ of $0.75 \%$ trifluoroacetic acid (TFA), 60\% acetonitrile, $300 \mathrm{mg} / \mathrm{ml} \mathrm{lac-}$ tic acid (solution A), loaded onto home-made titanium tips [36], equilibrated with solution $\mathrm{A}$ and washed with solution A supplemented with $0.1 \%$ TFA and $80 \%$ acetonitrile $(\mathrm{ACN})$. Samples were eluted twice with $0.5 \%$ ammonium hydroxide and $0.5 \%$ piperidine. Eluted fractions were acidified with formic acid (FA) and dried in a Speedvac. Peptides were resuspended in $2 \%$ ACN/0.1\% FA for LC-MS/MS analysis (liquid chromatography MS). MS analysis was performed on an LTQ Orbitrap XL (Thermo Fisher Scientific) equipped with a nanoACQUITY system (Waters). Tandem MS was carried out in an information-dependent mode, in which each full MS analysis was followed by three MS/MS acquisitions, with peptides selected for collision-induced dissociation (CID), to generate tandem mass spectra. The results of the data searches were imported into Scaffold (Version 3_00_8 Proteome Software) for the validation of protein identification. Mascot 2.3 (Matrix Science) and SEQUEST in Proteome Discoverer v.1.2 were used for data searches against a database for the human and mouse $\alpha$-syn forms, and spectra were validated by manual inspection.

\section{Production of recombinant proteins, in vitro phosphorylation assays and western blot analyses}

Early stop codons were introduced into the sequence of wild-type $\alpha$-syn, in the pT7.7 backbone, by single-site mutagenesis with complementary oligonucleotides $(\alpha-$ synD135, forward and reverse primers: gccttctgaggaa gggtatcaagactaetaacctgaagcctaag, cttaggcttcaggttattagtc ttgatacccttcctcagaaggc; $\alpha$-synY133, forward and reverse primers: ctgaggaagggtattaatgactacgaacctgaagcctaag, cttagg cttcaggttcgtagtcattaatacccttcctcag). All constructs were verified by sequencing. The recombinant proteins were produced and phosphorylated by Polo-like kinase 3 (PLK3, Invitrogen) as previously described $[37,38]$. Recombinant proteins were resolved by SDS-PAGE in 4-12\% polyacrylamide gels, electrotransferred to nitrocellulose membranes and probed with anti- $\alpha$-synD135 (1:400), anti- $\alpha$-synY133 (1:400) or anti- $\alpha$-syn (1:1000, Affiniti) antibodies. Antibody 
binding was visualized by incubation with secondary antirabbit IgG (1:50000, Jackson Laboratories) and enhanced chemiluminescence (West Pico Chemiluminescent substrate, Pierce or West Dura Extended Duration Substrate, Thermoscientific) with a Kodak Image J Station 4000 MM.

\section{Statistical analyses}

Unpaired two-tailed Student's $t$-tests were used to compare colocalization scores and the proportion of double-labeled neuronal cell bodies or processes between mouse genotypes hA30P $\alpha$-syn+/+ and parkin-/-; hA30P $\alpha-s y n+/+$. SAS software version 9.1 was used to analyze data from the behavioral study. The extension reflex and the footprint data were analyzed by repeated measures ANOVA, the factors used for the linear models being age and genotype. For the footprint analysis, the models included a linear, a quadratic and a cubic term and were adjusted for weight. Stepwise descending selection was used to eliminate nonsignificant terms to obtain the most parsimonious model; the difference from zero of each group was estimated with nested models. Two genotypes were considered to be significantly different if at least one of the linear, quadratic or cubic factors of the model differed between them. All of the differences observed concerned the cubic term. The $p$ values reported for each graph therefore correspond to the comparison of this term between groups. The final models were as follows:

(1) Symmetry of the hind limb extension reflex: wildtype $=0.03743$. weight $+0.985-0.00239$.age, hA30P $\alpha$-syn $+/+=0.03743$.weight $+1.0863-0.02742$ age -0.001548 . age $^{2}-0.00003$.age ${ }^{3}$, parkin $+/-;$ hA30P $\alpha-$ syn $+/+=0.03743$. weight $+0.9866-0.02692$.age -0.000889. age $^{2}-0.00001$. age $^{3}$, parkin-/-; hA30P $\alpha$-syn $+/+=0.03743$. weight + $1.0286-0.0143$.age +0.000664 .age ${ }^{2}-0.00000984$. age $^{3}$, parkin-/-; hA30P $\alpha$-syn $+/-=0.03743$. weight + 0.9833, parkin $-/-=0.03743$. weight +1.0504 .

(2) Amplitude of the hind limb extension reflex: wildtype $=0.1311$.weight $+0.8324-0.2131$.age +0.005619. age $^{2}-$ 0.00005. age $^{3}$, hA30P $\alpha-$ syn $+/+=0.1311$.weight -0.00003 . age $^{3}$, parkin +/-; hA30P $\alpha-$ syn $+/+=0.1311$.weight -0.00002 . age $^{3}$, parkin-/-; hA30P $\alpha$-syn $+/+=0.1311$.weight $+1.2297-$ 0.05299.age +0.00021 . age $^{2}$, parkin-/-; hA30P $\alpha-$ syn $+/-=$ 0.1311 .weight +0.9174 , parkin $-/-=0.1311$.weight $+1.3363-$ 0.00021.age . $^{2}$.

(3) Rotarod test: wild-type $=2.6585$.weight $+110.04-$ 1.41.age +0.016. age $^{2}$, hA30P $\alpha-$ syn $+/+=2.6585$. weight + 138.88 - 5.42.age +0.223. age $^{2}-0.00435$. age $^{3}$, parkin + /-;

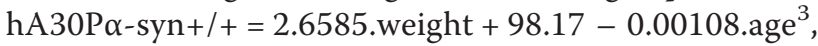
parkin-/-; hA30P $\alpha-s y n+/+=2.6585$.weight $+112.46-$ 0.00054.age ${ }^{3}$, parkin-/-; hA30P $\alpha$-syn $+/-=2.6585$. weight + 107.98, parkin $-/-=2.6585$. weight +110.72 .

(4) Length of forelimb stride: wild-type $=0.5815$.weight + $5.1139-0.00000832$. age $^{3}$, hA30P $\alpha$-syn $+/+=0.5815$.weight $+4.6383+0.004034$. age $^{2}-0.00015$. age $^{3}$, parkin + /-;
hA30P $\alpha$-syn $+/+=0.5815$.weight $+5.3843-0.1668$.age +

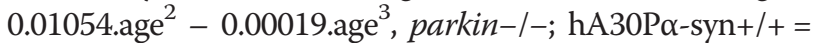
0.5815.weight $+5.5677-0.03991$.age, parkin-/-; hA30P $\alpha-$ syn $+/-=0.5815$.weight +5.0679 parkin $-/-=0.5815$.weight +5.0634 .

\section{Results}

Parkin depletion delays the appearance of motor dysfunction in a dose-dependent manner in hA30Pa-syn mice

We previously reported that the loss of both alleles of parkin significantly delayed the onset of hindlimb extension reflex asymmetry and the decline of rotarod performance in hA30P $\alpha$-syn mice [16]. We evaluated the effects of a single dysfunctional parkin allele on disease-related changes in motor function in this model, by analyzing in more detail the behavior of hA30P $\alpha$-syn mice with no, one, or two dysfunctional parkin alleles during a longitudinal follow-up study. We assessed the performance of the animals in three behavioral tasks: the hindlimb extension reflex, analyzed here not only for loss of symmetry, but also for decline in amplitude, (2) the rotarod test and (3) the footprint test (Figure 1). The extension reflex data confirmed the progressive impairment previously reported in hA30P $\alpha$-syn mice $(p<0.0001$ versus wild-type mice) and its significantly later onset in mice with two dysfunctional parkin alleles $(p<0.0001$ for symmetry and $p<0.01$ for amplitude versus hA30P $\alpha-s y n+/+$; Figure 1A,B) [16]; a similar delay was observed for hA30P $\alpha$-syn with a single dysfunctional parkin knockout allele $(p<0.0001$ for symmetry and $p<0.01$ for amplitude versus hA30P $\alpha$-syn+/+). Similarly, the mean rotarod performances of hA30P $\alpha$-syn mice declined with age $(p<0.0001$ versus wild-type mice; Figure $1 \mathrm{C})$, and this loss of performance was delayed in the absence of functional parkin alleles $(p<0.01$ versus hA30P $\alpha$-syn $+/+)$; a significant, but less pronounced delay, was also observed with a single parkin knockout allele $(p<0.01$ versus hA30P $\alpha-$ syn $+/+$ and $p<0.0001$ versus parkin-/-; hA30P $\alpha-s y n+/+)$. An analysis of gait characteristics in the footprint test confirmed these observations (Figure 1D): the mean length of forepaw strides decreased with age in hA30P $\alpha$-syn mice $(p<0.0001$ versus wild-type mice); this decrease was delayed in mice with no functional parkin alleles $(p<0.01$ versus hA30P $\alpha-$ syn $+/+)$ and, to a lesser extent, in hA30P $\alpha$-syn mice with a single functional parkin allele $(p<0.05$ versus parkin-/-; hA30P $\alpha-$ syn+/+).

Extension amplitude emerged as the earliest presymptomatic impairment in each group, followed by a decline in performance of the rotarod task, asymmetry in hindlimb extension and a decrease in stride length (Table 1). In each task, hA30P $\alpha$-syn mice with a single dysfunctional parkin allele had an intermediate phenotype, 


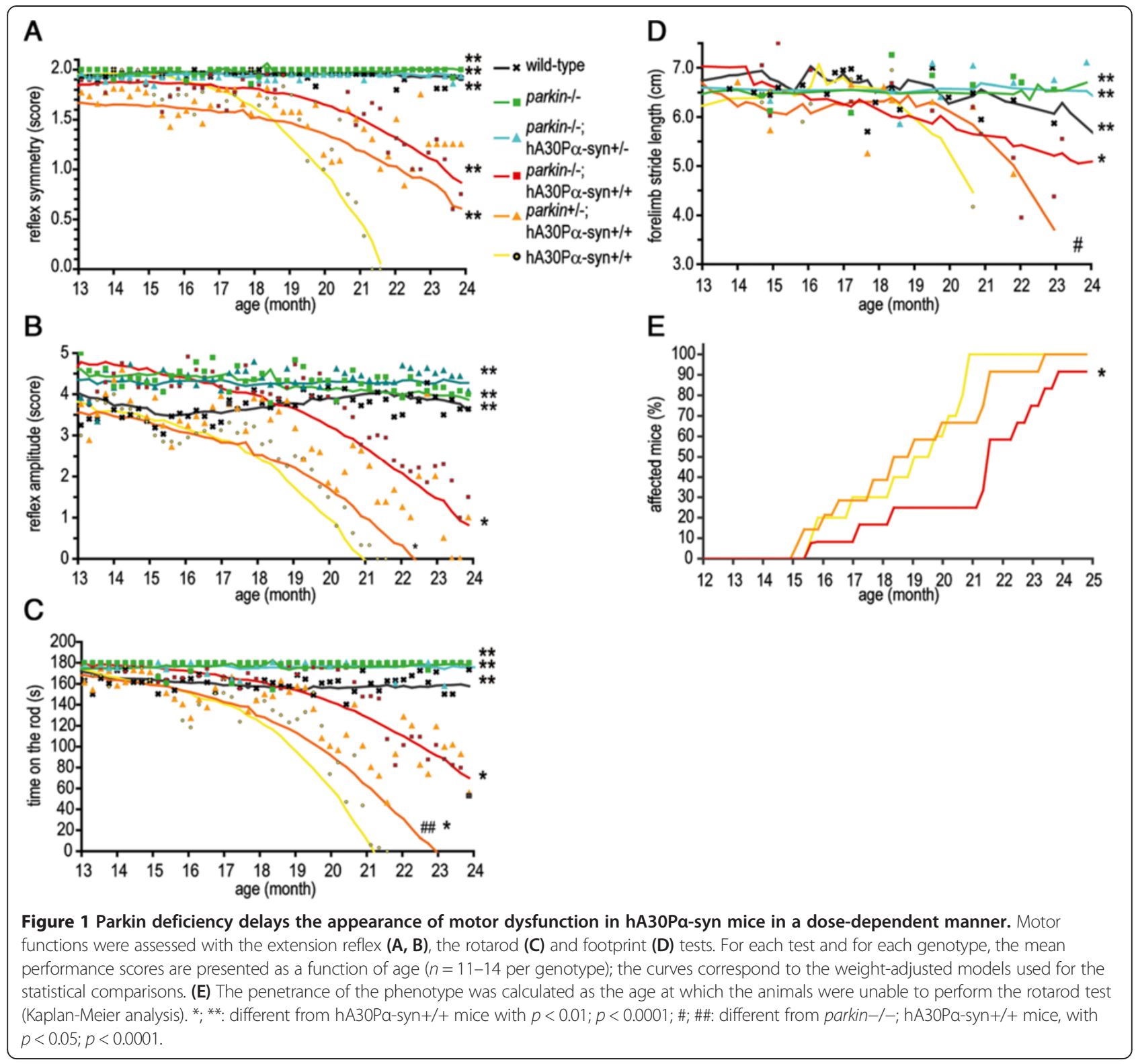

between that of hA30P $\alpha$-syn mice with no dysfunctional allele and that of hA30P $\alpha$-syn mice with two dysfunctional parkin alleles. The absence of Parkin lowered the penetrance of the phenotype, defined as the proportion of animals unable to perform the rotarod task at a given age (Figure 1E), whereas the partial depletion of Parkin had no such effect.
Truncated a-syn species found in LB accumulate in symptomatic hA30Pa-syn mice in the presence and absence of Parkin

We explored the mechanisms underlying the protection associated with Parkin deficiency, by comparing the accumulation of pathological $\alpha$-syn species in diseased hA30P $\alpha$-syn mice with functional parkin, and in hA30P $\alpha$-syn mice with

Table 1 Age by which a $50 \%$ decrease in the mean test performance of each group had occurred, or a $25 \%$ decrease in the case of the footprint test, within a confidence interval of one week, determined from the mathematical models established

\begin{tabular}{llll}
\hline & $\begin{array}{l}\text { Amplitude of extension reflex } \\
\text { score }<\mathbf{2 . 5}\end{array}$ & $\begin{array}{l}\text { Rotarod time on rod } \\
<\mathbf{9 0 ~ s}\end{array}$ & $\begin{array}{l}\text { Symmetry of extension reflex } \\
\text { score }<\mathbf{1}\end{array}$ \\
\hline hA30Pa-syn+/+ & $18.1 \pm 0.2$ months & $19.3 \pm 0.2$ months & $20.0 \pm 0.2$ months \\
parkin+/-; hA30Pa-syn+/+ $\mathbf{~ c m ~}$ & $18.4 \pm 0.2$ months & $20.2 \pm 0.2$ months & $22.3 \pm 0.2$ months \\
parkin-/-; hA30Pa-syn+/+ & $21.0 \pm 0.2$ months & $23.2 \pm 0.2$ months & $23.4 \pm 0.2$ months \\
\hline
\end{tabular}


no functional parkin alleles. Enrichment in $\alpha$-synD135 or $\alpha$-synY133 has been reported in the brains of PD patients studied by biochemical techniques [2]. We investigated the accumulation of these species in hA30P $\alpha$-syn mice, using recently developed antibodies that we validated by western blotting and immunohistochemistry. These antibodies could not detect amounts below $1 \mu \mathrm{g}$ of their cognate recombinant protein, thus limiting their value for biochemical studies (Figure 2A). However, the analysis of more than 50 LB in substantia nigra sections from three cases of sporadic PD revealed immunostaining for $\alpha$ synD135 in more than $90 \%$ of these inclusions, detected with $\mathrm{P}^{\mathrm{S} 129} \alpha$-syn antibodies (Figure $2 \mathrm{~B}$ ). No such staining was observed when the anti- $\alpha$-synD135 antibody was preabsorbed with $\alpha$-synD135, whereas prior incubation with the full-length $\alpha$-syn did not abolish the signal (Figure 2C). By contrast, the preabsorption experiment revealed nonspecific staining with the antibody against $\alpha$-synY133 (data not shown). This antibody was therefore not used in subsequent experiments.

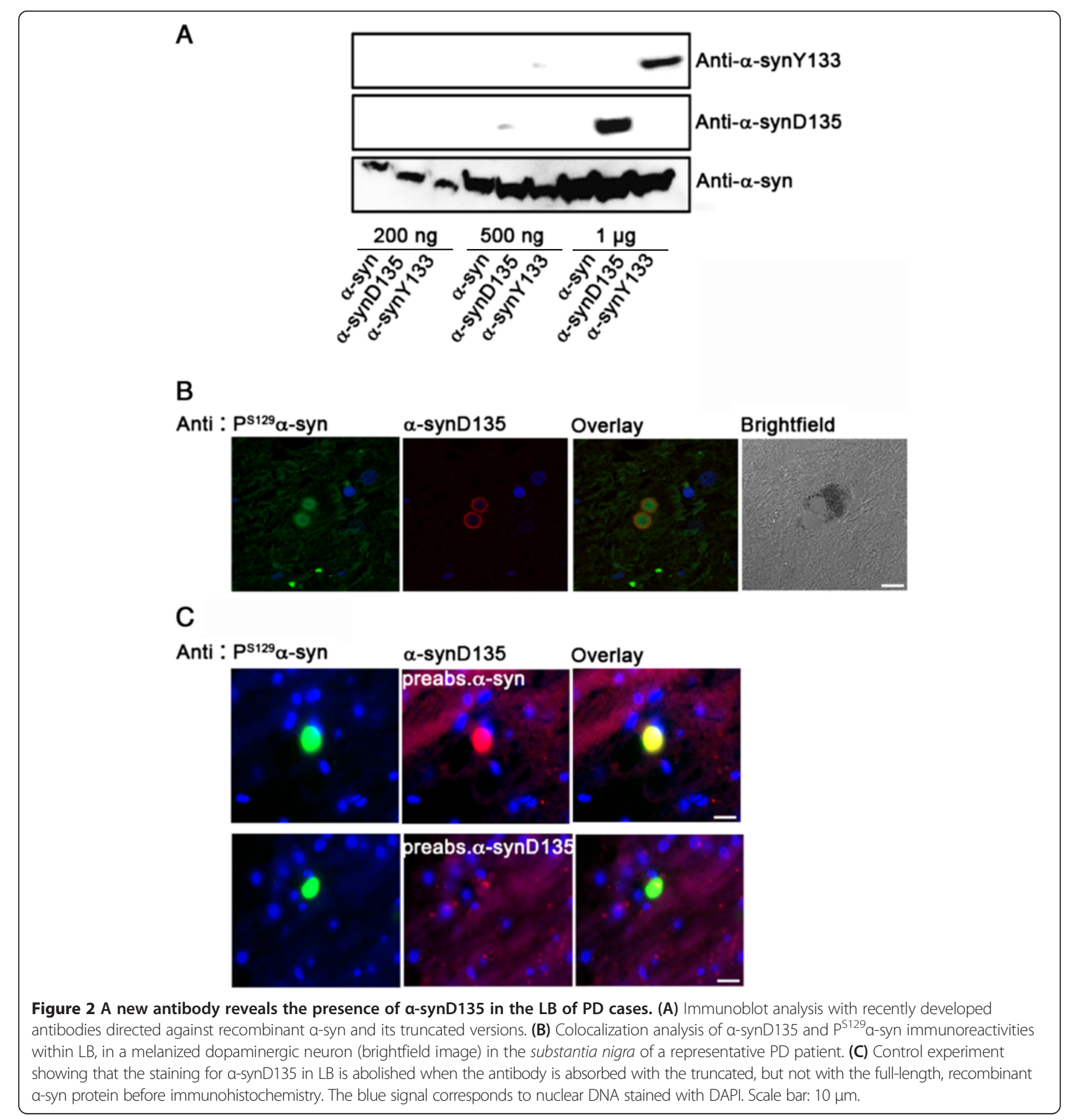


We then investigated the accumulation of $\alpha$-synD135 species in hA30P $\alpha$-syn mice with functional or dysfunctional parkin. In the brainstem of symptomatic animals, the anti- $\alpha$-synD135 antibody labeled numerous normally shaped or swollen processes and cell bodies (Figure 3A). This labeling was abolished by prior absorption with recombinant $\alpha$-synD135 (Figure 3A), and was not detected in the brains of healthy hA30P $\alpha$-syn mice, regardless of their expression status for parkin, or in non transgenic animals (Figure $3 \mathrm{~B}$ and data not shown).
Qualitative comparisons of symptomatic hA30P $\alpha$-syn mice and hA30P $\alpha$-syn mice with no functional parkin alleles revealed no obvious differences attributable to Parkin deficiency in terms of the type of structures labeled (processes versus cell bodies) or the density of deposits (data not shown). MS analyses of brain lysates from symptomatic mice unambiguously identified the presence of $\alpha$-syn and $\alpha$-synD135 in both hA30P $\alpha$-syn mice and hA30P $\alpha$-syn mice lacking Parkin (representative spectrum shown in Figure $3 \mathrm{C}$ ). By contrast, the

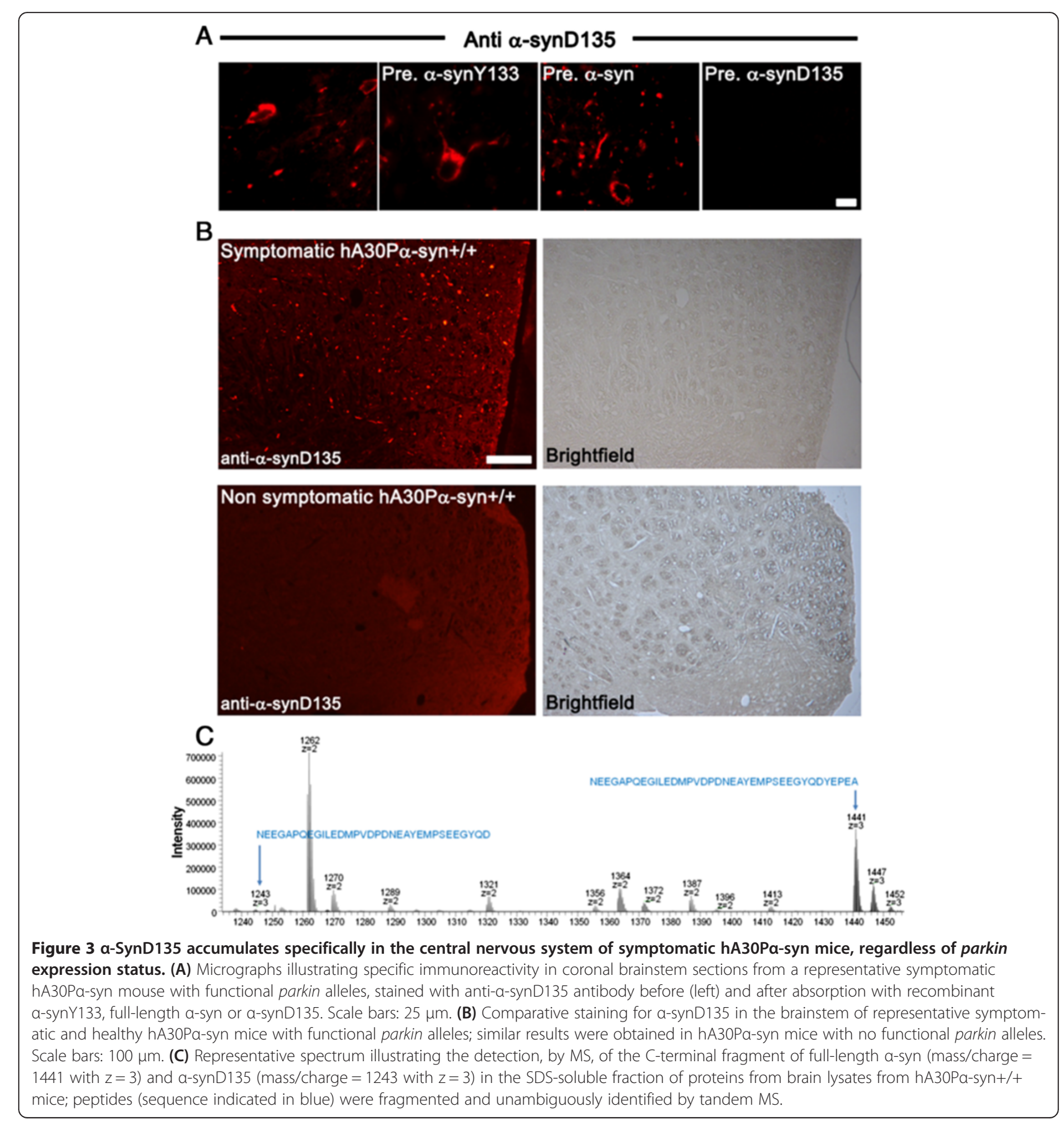


signal potentially corresponding to $\alpha$-synY133 was weak in all cases, precluding clear identification of this species (Table 2).

The a-synD135 species deposited are preferentially associated with $\mathrm{P}^{\mathrm{S} 129} \mathrm{a}$-syn in the presence and absence of Parkin In our previous study, we reported that ubiquitin immunoreactivity invariably colocalized with $\mathrm{P}^{\mathrm{S} 129} \alpha$-syn staining in symptomatic hA30P $\alpha$-syn mice. In addition, the $\mathrm{P}^{\mathrm{S} 129} \alpha$-syn deposits in neuronal cell bodies and processes were less frequently associated with ubiquitin in mice with no functional parkin alleles than in mice with functional parkin [16]. Confocal analysis of a larger group of animals in this study confirmed the colocalization of ubiquitin staining and $\mathrm{P}^{\mathrm{S} 129} \alpha$-syn deposits in symptomatic hA30P $\alpha$-syn mice, regardless of their parkin status (Figure 4A, representative Pearson's correlation coefficient: $0.8 \pm 0.07$; Figure $5 \mathrm{~A}$ ). We also confirmed that the proportion of $\mathrm{P}^{\mathrm{S} 129} \alpha$-syn-positive cell bodies associated with ubiquitin staining was lower in mice with no functional parkin alleles than in mice with functional parkin (Figure 5D, left graph). However, this difference was not significant for neuronal processes.

We investigated whether $\alpha$-synD135 was phosphorylated or ubiquitylated and whether there were differences in these modifications associated with Parkin deficiency, by performing double immunofluorescence staining on brain sections from symptomatic hA30P $\alpha$-syn mice with functional parkin or with no functional parkin alleles. Staining for $\alpha$-synD135 was significantly less abundant than staining for $\mathrm{P}^{\mathrm{S} 129} \alpha$-syn (Figure $5 \mathrm{~B}$ ) and ubiquitin (Figure $5 \mathrm{C}$ ), in mice of both genotypes. Consistent with the observations in LB, most $\alpha$-synD135 immunoreactivity was found to be associated with $\mathrm{P}^{\mathrm{S} 129} \alpha$-syn-positive deposits (Figure 5B and Figure 5D, second graph from the left). However, it often did not cover the entire $\mathrm{P}^{\mathrm{S} 129} \alpha$-syn-positive structure within a particular neuronal cell body or process, or extended beyond it (Figure 5B). The degree of colocalization within regions displaying both types of

Table 2 Summary of the a-syn species detected by MS in brain lysates from two hA30Pa-syn mice with functional parkin (column \# 1-2) and three hA30Pa-syn mice lacking both parkin alleles (column \# 3-5)

\begin{tabular}{|c|c|c|c|c|c|c|}
\hline & & \multicolumn{2}{|c|}{ hA30Pa-syn+/+ } & \multicolumn{3}{|c|}{ parkin-/-; hA30Pa-syn+/+ } \\
\hline & & $\# 1$ & $\# 2$ & \# 3 & $\# 4$ & $\# 5$ \\
\hline \multirow[t]{3}{*}{ Human } & a-syn & ++ & ++ & ++ & ++ & ++ \\
\hline & a-synD135 & ++ & ++ & - & + & ++ \\
\hline & a-synY133 & - & - & - & - & - \\
\hline \multirow[t]{3}{*}{ Mouse } & a-syn & ++ & ++ & + & + & ++ \\
\hline & a-synD135 & - & - & - & - & - \\
\hline & a-synY133 & - & - & - & - & - \\
\hline
\end{tabular}

-: not detected; +: identified with a probability between $80 \%$ and $94 \%$; ++ : identified with a probability $>95 \%$.

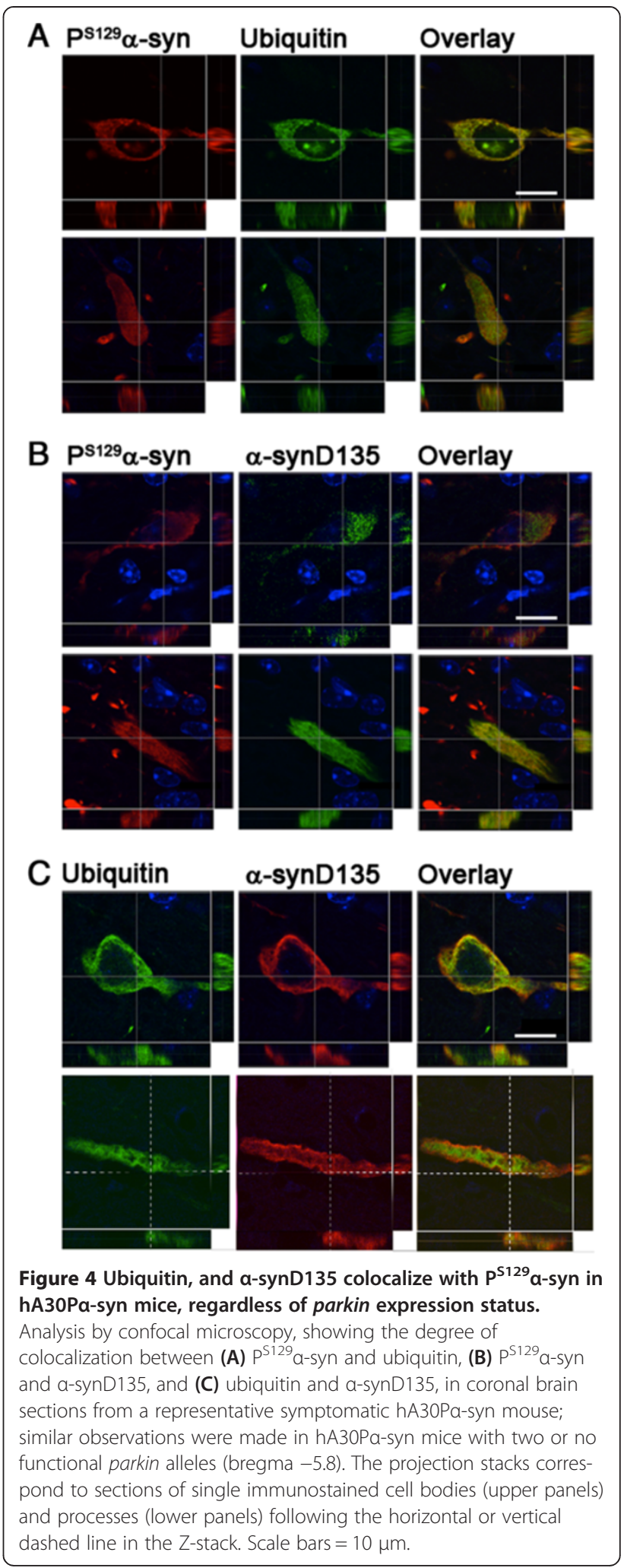

immunoreactivity was high, regardless of parkin expression status (Figure 4B, representative Pearson's correlation coefficient: $0.9 \pm 0.04) . \alpha$-SynD135 and ubiquitin 


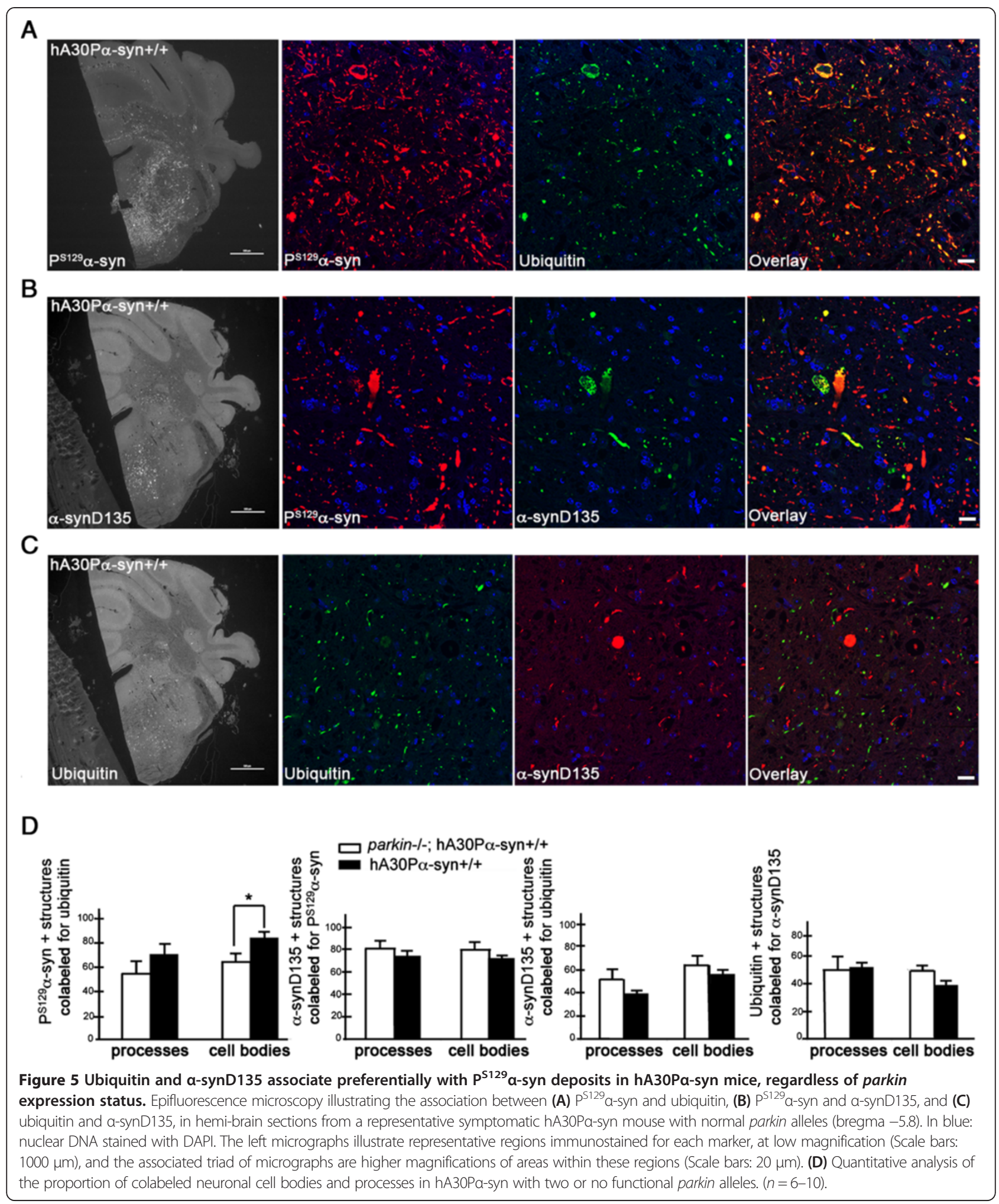

colocalized in some neurons, but were also observed independently of each other in approximately $50 \%$ of the neuronal cell bodies and processes in symptomatic hA30P $\alpha$ syn mice, regardless of parkin expression status (Figure 4C, representative Pearson's correlation coefficients: $0.8 \pm 0.03$; Figure $5 \mathrm{C}$ and $\mathrm{D}$, graphs on the right).

We investigated the effect of truncation on $\alpha$-syn phosphorylation at S129, by performing in vitro phosphorylation 
assays with PLK3, which is known to phosphorylate $\alpha$-syn efficiently and specifically at S129 [37,39]. After $15 \mathrm{~h}$, the entire pool of full-length $\alpha$-syn was phosphorylated by PLK3, whereas the $\alpha$-synY133 variant was only partially converted and phosphorylated $\alpha$-synD135 was undetectable after $15 \mathrm{~h}$ (Figure 6).

\section{$\mathrm{P}^{\mathrm{S} 129} \mathrm{a}$-syn accumulates as fibrillar species in symptomatic} hA30Pa-syn mice with and without Parkin

We used electron microscopy coupled to anti- $\mathrm{P}^{\mathrm{S} 129} \alpha-$ syn-specific immunostaining to investigate the nature of the deposits in regions of the brainstem in which a massive accumulation of this protein was observed and to explore potential differences associated with Parkin deficiency. Abundant fibrils loosely associated and diffusely distributed throughout the cytosol of neurons or in neuronal processes were observed with secondary antibodies conjugated to horseradish peroxidase, in mice of both genotypes (representative images shown in Figure 7A-C). There were no dense inclusions. The fibrils were generally more densely packed in the neuronal processes than in the cell bodies, and were, in some cases, confined to the proximity of the plasma membrane (Figure 7C). These fibrils were approximately 10-15 nm wide, as estimated for deposits immunostained with secondary antibodies coupled to gold beads (Figure 7D). Similar configurations were found in
hA30P $\alpha$-syn mice with functional parkin and with no functional parkin alleles.

\section{Discussion}

This study confirms and extends our previous work showing that the loss of both parkin alleles significantly delays sensorimotor impairment related to the progression of $\alpha$-synucleinopathy in hA30P $\alpha$-syn mice [16]. We report here the results of a more complete comparative behavioral longitudinal follow-up study of hA30P $\alpha$-syn mice with two functional parkin alleles, or with the loss of one or both parkin alleles. In addition to the rotarod task and the analysis of hindlimb reflex symmetry, we used the hindlimb reflex amplitude and footprint tests to evaluate the behavior of the animals. Strikingly, this follow-up not only confirmed our previous results, but also revealed a protective effect of the loss of a single parkin allele. In addition, Parkin depletion had a clear dose-dependent effect on performance in the rotarod task, with different performance curves for hA30P $\alpha$-syn mice with two, one or no functional parkin alleles.

The loss of parkin expression delayed sensorimotor impairment in hA30P $\alpha$-syn mice, but only slightly modified neuropathological presentation in end-stage disease. The extent and intensities of the immunoreactivities against ubiquitin, $\mathrm{P}^{\mathrm{S} 129} \alpha$-syn and $\alpha$-syn truncated at D135 were generally similar in hA30P $\alpha$-syn mice with and without

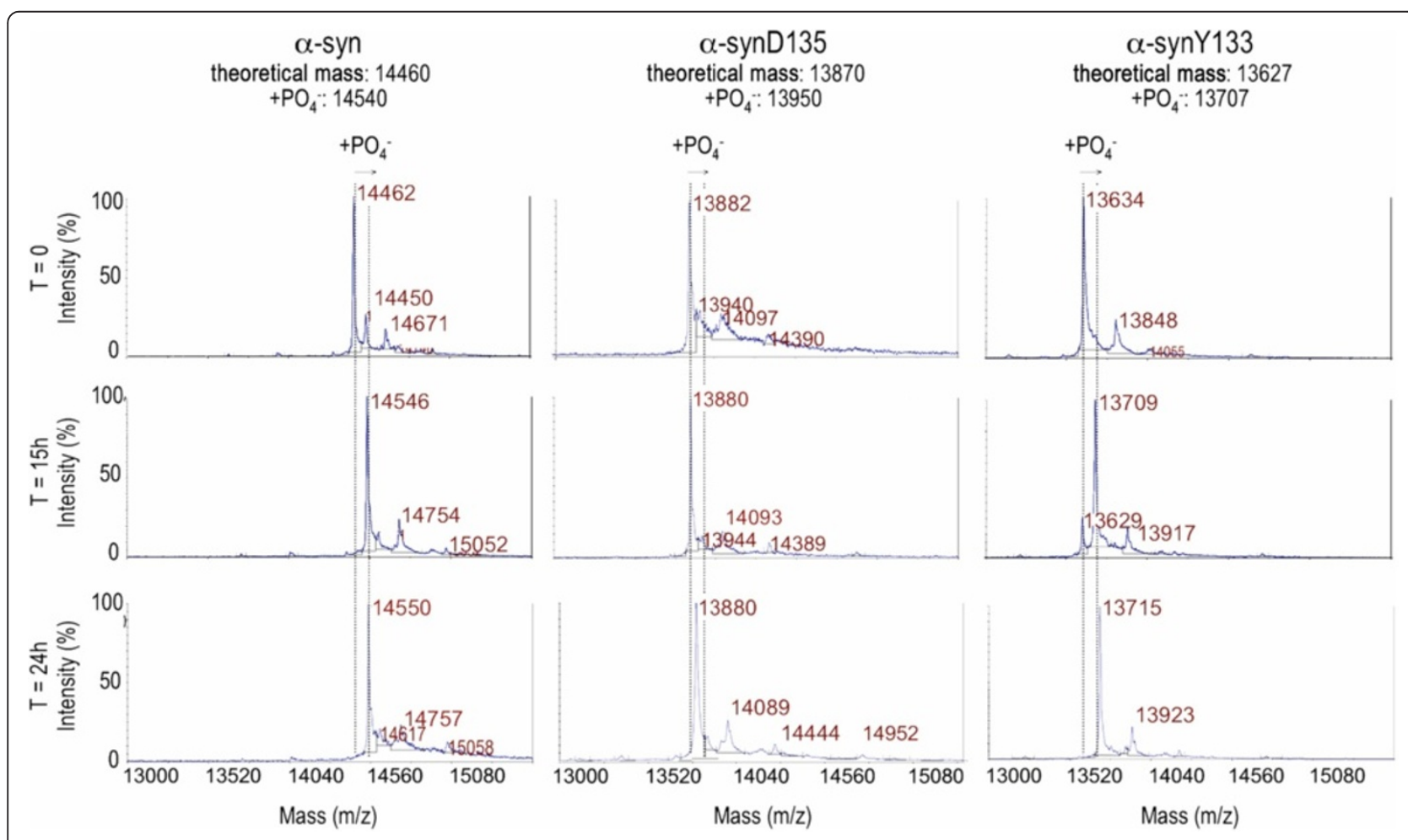

Figure 6 PLK3 does not phosphorylate a-synD135 efficiently in vitro. MALDI-TOF time-point analyses of the phosphorylation of recombinant a-syn, a-synD135 and a-synY133 by PLK3: the mass increase of approximately 80 Da corresponds to the addition of one phosphate group. 


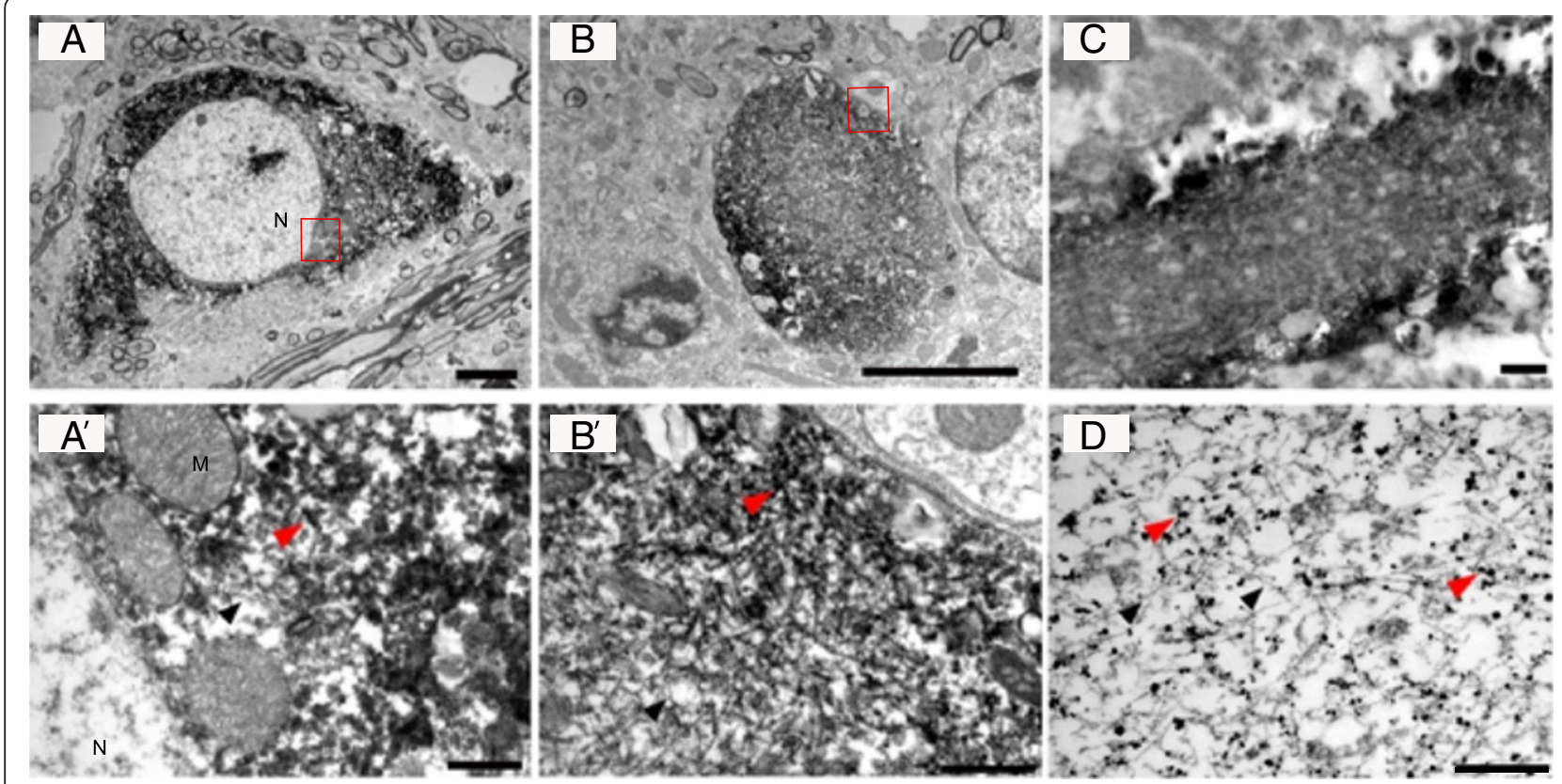

Figure $7 \mathrm{P}^{\mathrm{S129}} \mathrm{a}$-syn accumulates in fibrillar deposits in hA30Pa-syn mice. Representative electron micrographs illustrating a cell body (A) and a process sectioned transversally (B) or longitudinally (C) and immunostained with $P^{5129} a-s y n$ antibodies and secondary antibodies coupled to horseradish peroxidase from a representative symptomatic hA30Pa-syn mouse expressing parkin. ( $\left.\mathbf{A}^{\prime}-\mathbf{B}^{\prime}\right)$ are higher magnifications of the framed regions in (A) and (B). (D) Nanogold staining of a $\mathrm{P}^{\mathrm{S} 129} \mathrm{a}$-syn deposit within a neuronal process. Arrowheads indicate fibrils with (red) or without (black) associated $\mathrm{P}^{\mathrm{S} 129} \mathrm{a}$-syn staining; $\mathrm{N}$ (nucleus), M (mitochondria). Similar results were obtained in hA30Pa-syn mice with two or no functional parkin alleles. Scale bars: $4 \mu \mathrm{m}$ in (A) and (B), and $0.5 \mu \mathrm{m}$ in $\left(\mathbf{A}^{\prime}\right),\left(\mathbf{B}^{\prime}\right),(\mathbf{C})$ and (D).

parkin expression. Consistent with the current hypothesis that $\alpha$-syn phosphorylated at S129 plays a key role in the neuropathological process, $\mathrm{P}^{\mathrm{S} 129} \alpha$-syn was deposited as loose fibrils throughout the brainstem and the spinal cord in affected animals only, regardless of parkin expression status. In hA30P $\alpha$-syn mice of both parkin genotypes, some of the $\mathrm{P}^{\mathrm{S} 129} \alpha$-syn-positive deposits colocalized with immunostaining for ubiquitin or $\alpha$-synD135, which were significantly less widely distributed than the $\mathrm{P}^{\mathrm{S} 129} \alpha$-syn staining, consistent with observations in human brains affected by $\alpha$-synucleinopathy. Ubiquitin and $\alpha$-synD135 were mostly found concomitantly with $\mathrm{P}^{\mathrm{S} 129} \alpha$-syn, indicating that ubiquitylation and C-terminal truncation at D135 are secondary PTM. As reported in our previous study [16], the proportion of $\mathrm{P}^{\mathrm{S} 129} \alpha$-syn deposits in neuronal cell bodies associated with ubiquitin was lower in hA30P $\alpha$-syn mice lacking both parkin alleles than in hA30P $\alpha$-syn mice with functional parkin alleles, possibly indicating less advanced $\alpha$-synucleinopathy. By contrast, parkin dysfunction was not associated with any significant difference in the proportion of $\mathrm{P}^{\mathrm{S} 129} \alpha$ syn deposits costained for $\alpha$-synD135, or in the degree of colocalization between $\alpha$-synD135- and ubiquitinimmunoreactive protein deposits in the neuronal somata or processes of hA30P $\alpha$-syn mice. It is widely accepted that ubiquitylation is primarily associated with $\mathrm{P}^{\mathrm{S} 129} \alpha$-syn in human $\alpha$-synucleinopathies, but less is known about the crosstalk between S129 phosphorylation and C-terminal truncation. Anderson et al. [2] reported that all peptides corresponding to the $\alpha$-synY133 fragment identified by MS were phosphorylated at S129 in LB fractions [2]. We found that recombinant $\alpha$-synY133 and $\alpha$ synD135 proteins were less well phosphorylated by PLK3 than the full-length protein in vitro [37,39], suggesting that C-terminal truncation does indeed occur once the protein has been phosphorylated. However, the partial dissociation between immunostaining for $\alpha$-synD135 and that for $\mathrm{P}^{\mathrm{S} 129} \alpha$-syn often observed in the double-labeled neuronal cell bodies and processes of hA30P $\alpha$-syn mice, regardless of parkin expression, suggests that $\alpha$-syn truncation at D135 may also arise independently of phosphorylation on S129. Alternatively, there may be interference between the two types of immunohistochemical staining, due to the physical proximity of the PTM examined: it is not unlikely, for example, that a deposit of $\mathrm{P}^{\mathrm{S} 129} \alpha$-syn with a high proportion of truncated protein is less efficiently recognized by antibodies specific for the phosphorylated species.

There is some debate about whether the ubiquitylation of $\alpha$-syn constitutes a proteasomal degradation signal [1], but proteasome dysfunction, which is thought to occur during the progression of $\alpha$-synucleinopathy [29,40,41], may generate $\mathrm{C}$-terminally cleaved $\alpha$-syn fragments $[12,42]$. However, the random nature of the association between the patterns of immunostaining for ubiquitin and 
$\alpha$-synD135 in our study is not consistent with ubiquitylation playing a role in the generation of such fragments.

Despite the mitigation of the preclinical $\alpha$-syn-related phenotype revealed by our longitudinal behavioral followup study, the partial depletion of Parkin did not delay overt manifestation of the neurological phenotype in hA30P $\alpha-$ syn mice. The lack of impact of Parkin deficiency on disease penetrance and progression reported in hA53T $\alpha$-syn mice [31], therefore does not exclude a moderate modifier effect, as the study concerned was based on late-stage neurological phenotypes and single-point analyses of specific behavioral measures. Alternatively, the absence of interaction between Parkin and $\alpha$-synA53T may reflect different effects of Parkin deficiency on the pathological alterations caused by different $\alpha$-syn variants [31]. However, a recent in vitro study reported the rescue of cortical neurons from the harmful effects of $\alpha$-synA53T toxicity by siRNAmediated downregulation of the parkin gene, supporting the notion that there is a beneficial modifier effect associated with this condition [43].

\section{Conclusion}

In conclusion, we confirm here that Parkin depletion modifies $\alpha$-syn-induced neurodegeneration in hA30P $\alpha$-syn mice. The loss of a single functional parkin allele was sufficient to delay the appearance of preclinical signs of motor dysfunction in this model, albeit to a lesser extent than observed with the loss of both alleles, with no effect on appearance of overt disease signs. An analysis of the $\alpha$-syn protein deposits revealed possible interplay between PTM: ubiquitylation and truncation at D135 were associated preferentially with $\mathrm{P}^{\mathrm{S} 129} \alpha$-syn, whereas ubiquitylation and $\alpha$-synD135 were found both independently and in association. The distribution and composition of the $\mathrm{P}^{\mathrm{S} 129} \alpha-$ syn deposits were similar in the presence and absence of Parkin in the end stage of disease, suggesting that a loss of Parkin function does not fundamentally alter the nature of events leading to protein accumulation in this mouse model. A detailed quantitative investigation of the proteins, signaling and degradation pathways thought to regulate $\alpha$-syn-dependent neurodegeneration during the preclinical and early symptomatic stages of the disease might shed light on the mechanisms underlying the neuroprotection associated with Parkin deficiency in future studies.

\footnotetext{
Abbreviations

PD: Parkinson's disease; LB: Lewy bodies; a-syn: a-synuclein; PTM: Posttranslational modifications; $\mathrm{P}^{5129} \mathrm{a}-\mathrm{syn}$ : $\mathrm{a}-\mathrm{syn}$ phosphorylated at S129; hA30a-syn: Mouse model producing the pathogenic human A30P variant of a-syn; a-synD135 and a-synY133: a-syn truncated at D135 and Y133; hA30Pa-syn: Human A30P variant of a-syn; MS: Mass spectrometry; PLK3: Polo-like kinase 3; SDS: Sodium dodecyl sulfate; PBS: Phosphatebuffered saline; BSA: Bovine serum albumin; NGS: Newborn goat serum; PFA: Paraformaldehyde; TFA: Trifluoroacetic acid; ACN: Acetonitrile; FA: Formic acid.
}

Competing interests

None of the authors has any conflict of interest to report.

\section{Authors' contributions}

MF designed, performed the behavioral study and the in vitro experiments, analyzed the data and wrote the manuscript. AR designed, performed the immunohistological characterization, experiments, analyzed the data and wrote the manuscript. JG genotyped the animals and participated in the behavioral analyses. MPM performed electron microscopy experiments. PB and STM analyzed the behavioral data. HAL provided recombinant a-syn, participated in the design of the in vitro experiments and helped draft the manuscript. JPA helped draft the manuscript. JPA, RB and JH generated the antibodies against truncated a-syn. AB participated in study design and reviewed the manuscript. OC designed the study, analyzed the data and wrote the manuscript. All authors have read and approved the manuscript.

\section{Acknowledgment}

This work was supported by Institut National de la Santé et de la Recherche Médicale, Fédération pour la Recherche sur le Cerveau, Fondation de France, Fondation ICM, APOPIS (an integrated project funded by the EU under the Sixth Framework Programme; Priority: Life Science for Health, contract no. LSHM-CT-2003-503330). MF and AR were supported by the French Ministry of Research. MF was also supported by the Fondation pour la Recherche Médicale, and AR by the Association France Parkinson. We thank M Moniatte, $R$ Hamelin, D Chiappe (Proteomic Core Facility, EPFL, Lausanne) and N Jordan (Laboratory of Molecular Neurobiology and Neuroproteomics, EPFL, Lausanne) for excellent technical support. Confocal images were acquired at the Plate-forme d'Imagerie Cellulaire Pitié-Salpêtrière (Hôpital de la Pitié-Salpêtrière, Paris). hA30Pa-syn mice for breeding were kindly provided by PJ Kahle (Hertie Institute for Clinical Brain Research, Tübingen) and human tissue was provided by the GIE NeuroCEB (Hôpital de la Pitié-Salpêtrière, Paris).

\section{Author details}

${ }^{1}$ Inserm, U 975, CRICM, Hôpital de la Pitié-Salpêtrière, F-75013 Paris, France. ${ }^{2}$ UPMC Université Paris 06, UMR_S975, F-75013, Paris, France. ${ }^{3}$ CNRS, UMR 7225, F-75013, Paris, France. ${ }^{4}$ Laboratory of Molecular Neurobiology and Chemical Biology of Neurodegeneration, Brain Mind Institute, Ecole Polytechnique Fédérale de Lausanne, Lausanne $\mathrm{CH}-1015$ Switzerland. ${ }^{5}$ Université Pierre et Marie Curie-Paris 6, ER4 Modeling in Clinical Research, Paris F-75013 France. ${ }^{6}$ Elan Pharmaceuticals, 180 Oyster Point Blvd, South San Francisco, California, CA 94080 USA. ${ }^{7}$ Department of Biostatistics and Medical Informatics, Hôpital de la Pitié-Salpêtrière, Assistance Publique-Hôpitaux, 47 Boulevard de I'Hôpital, Paris F-75013 France. ${ }^{8}$ AP-HP, Hôpital de la Salpêtrière, Department of Genetics and Cytogenetics, F-75013 Paris, France. ${ }^{9}$ Current address: Center for Psychiatric Neuroscience, Department of Psychiatry, Lausanne University Hospital, Prilly-Lausanne, CH 1008 Switzerland.

Received: 27 May 2013 Accepted: 28 October 2013

Published: 5 November 2013

\section{References}

1. Oueslati A, Fournier M, Lashuel HA: Role of post-translational modifications in modulating the structure, function and toxicity of alpha-synuclein: implications for Parkinson's disease pathogenesis and therapies. Prog Brain Res 2010, 183:115-145.

2. Anderson JP, Walker DE, Goldstein JM, de Laat R, Banducci K, Caccavello RJ, Barbour R, Huang J, Kling K, Lee M, et al: Phosphorylation of Ser-129 is the dominant pathological modification of alpha-synuclein in familial and sporadic Lewy body disease. J Biol Chem 2006, 281(40):29739-29752.

3. Fujiwara H, Hasegawa M, Dohmae N, Kawashima A, Masliah E, Goldberg MS, Shen J, Takio K, Iwatsubo T: Alpha-Synuclein is phosphorylated in synucleinopathy lesions. Nat Cell Biol 2002, 4(2):160-164.

4. Tofaris GK, Razzaq A, Ghetti B, Lilley KS, Spillantini MG: Ubiquitination of alpha-synuclein in Lewy bodies is a pathological event not associated with impairment of proteasome function. J Biol Chem 2003, 278(45):44405-44411.

5. Hasegawa M, Fujiwara H, Nonaka T, Wakabayashi K, Takahashi H, Lee VM, Trojanowski JQ, Mann D, Iwatsubo T: Phosphorylated alpha-synuclein is ubiquitinated in alpha-synucleinopathy lesions. J Biol Chem 2002, 277(50):49071-49076. 
6. Sampathu DM, Giasson BI, Pawlyk AC, Trojanowski JQ, Lee VM: Ubiquitination of alpha-synuclein is not required for formation of pathological inclusions in alpha-synucleinopathies. Am J Pathol 2003, 163(1):91-100

7. Rott R, Szargel R, Haskin J, Shani V, Shainskaya A, Manov I, Liani E, Avraham E, Engelender S: Monoubiquitylation of alpha-synuclein by seven in absentia homolog (SIAH) promotes its aggregation in dopaminergic cells. J Biol Chem 2008, 283(6):3316-3328.

8. Nonaka T, Iwatsubo T, Hasegawa M: Ubiquitination of alpha-synuclein. Biochemistry 2005, 44(1):361-368.

9. Baba M, Nakajo S, Tu PH, Tomita T, Nakaya K, Lee VM, Trojanowski JQ, Iwatsubo T: Aggregation of alpha-synuclein in Lewy bodies of sporadic Parkinson's disease and dementia with Lewy bodies. Am J Pathol 1998, 152(4):879-884.

10. Campbell BC, McLean CA, Culvenor JG, Gai WP, Blumbergs PC, Jakala P, Beyreuther K, Masters CL, Li QX: The solubility of alpha-synuclein in multiple system atrophy differs from that of dementia with Lewy bodies and Parkinson's disease. J Neurochem 2001, 76(1):87-96.

11. Li W, West N, Colla E, Pletnikova O, Troncoso JC, Marsh L, Dawson TM, Jakala P, Hartmann T, Price DL, et al: Aggregation promoting C-terminal truncation of alpha-synuclein is a normal cellular process and is enhanced by the familial Parkinson's disease-linked mutations. Proc Nat Acad Sci U S A 2005, 102(6):2162-2167.

12. Liu CW, Giasson BI, Lewis KA, Lee VM, Demartino GN, Thomas PJ: A precipitating role for truncated alpha-synuclein and the proteasome in alpha-synuclein aggregation: implications for pathogenesis of Parkinson disease. J Biol Chem 2005, 280(24):22670-22678.

13. Chen L, Periquet M, Wang X, Negro A, McLean PJ, Hyman BT, Feany MB: Tyrosine and serine phosphorylation of alpha-synuclein have opposing effects on neurotoxicity and soluble oligomer formation. J Clin Invest 2009, 119(11):3257-3265

14. Chung KK, Zhang Y, Lim KL, Tanaka Y, Huang H, Gao J, Ross CA, Dawson VL, Dawson TM: Parkin ubiquitinates the alpha-synuclein-interacting protein, synphilin-1: implications for Lewy-body formation in Parkinson disease. Nat Med 2001, 7(10):1144-1150.

15. Eslamboli A, Romero-Ramos M, Burger C, Bjorklund T, Muzyczka N, Mandel RJ, Baker $H$, Ridley RM, Kirik D: Long-term consequences of human alpha-synuclein overexpression in the primate ventral midbrain. Brain 2007, 130(Pt 3):799-815.

16. Fournier M, Vitte J, Garrigue J, Langui D, Dullin J-P, Saurini F, Hanoun N, Perez-Diaz F, Cornilleau F, Joubert C, et al: Parkin deficiency delays motor decline and disease manifestation in a mouse model of synucleinopathy. PLoS One 2009, 4(8):e6629.

17. Giasson BI, Duda JE, Quinn SM, Zhang B, Trojanowski JQ, Lee VM: Neuronal alpha-synucleinopathy with severe movement disorder in mice expressing A53T human alpha-synuclein. Neuron 2002, 34(4):521-533.

18. Lee MK, Stirling W, Xu Y, Xu X, Qui D, Mandir AS, Dawson TM, Copeland NG, Jenkins NA, Price DL: Human alpha-synuclein-harboring familial Parkinson's disease-linked Ala-53 - > Thr mutation causes neurodegenerative disease with alpha-synuclein aggregation in transgenic mice. Proc Natl Acad Sci U S A 2002, 99(13):8968-8973.

19. Lo Bianco C, Ridet JL, Schneider BL, Deglon N, Aebischer P: Alpha synucleinopathy and selective dopaminergic neuron loss in a rat lentiviral-based model of Parkinson's disease. Proc Natl Acad Sci U S A 2002, 99(16):10813-10818

20. Masliah E, Rockenstein E, Veinbergs I, Mallory M, Hashimoto M, Takeda A, Sagara Y, Sisk A, Mucke L: Dopaminergic loss and inclusion body formation in alpha-synuclein mice: implications for neurodegenerative disorders. Science 2000, 287(5456):1265-1269.

21. Neumann M, Kahle PJ, Giasson BI, Ozmen L, Borroni E, Spooren W, Muller V, Odoy S, Fujiwara H, Hasegawa M, et al: Misfolded proteinase K-resistant hyperphosphorylated alpha-synuclein in aged transgenic mice with locomotor deterioration and in human alpha-synucleinopathies. J Clin Invest 2002, 110(10):1429-1439.

22. Sato H, Arawaka S, Hara S, Fukushima S, Koga K, Koyama S, Kato T: Authentically phosphorylated alpha-synuclein at Ser129 accelerates neurodegeneration in a rat model of familial Parkinson's disease. J Neurosci 2011, 31(46):16884-16894.

23. van der Putten H, Wiederhold KH, Probst A, Barbieri S, Mistl C, Danner S, Kauffmann S, Hofele K, Spooren WP, Ruegg MA, et al: Neuropathology in mice expressing human alpha-synuclein. J Neurosci 2000, 20(16):6021-6029.

24. Yamada M, Iwatsubo T, Mizuno $Y$, Mochizuki H: Overexpression of alphasynuclein in rat substantia nigra results in loss of dopaminergic neurons, phosphorylation of alpha-synuclein and activation of caspase- 9 : resemblance to pathogenetic changes in Parkinson's disease. $J$ Neurochem 2004, 91(2):451-461.

25. Corti O, Lesage S, Brice A: What genetics tells us about the causes and mechanisms of Parkinson's disease. Physiol Rev 2011, 91(4):1161-1218.

26. Lucking CB, Durr A, Bonifati V, Vaughan J, De Michele G, Gasser T, Harhangi BS, Meco G, Denefle P, Wood NW, et al: Association between early-onset Parkinson's disease and mutations in the parkin gene. N Engl J Med 2000, 342(21):1560-1567.

27. Dawson TM, Dawson VL: The role of parkin in familial and sporadic Parkinson's disease. Mov Disord 2010, 25(Suppl 1):S32-39.

28. Haywood AF, Staveley BE: Parkin counteracts symptoms in a Drosophila model of Parkinson's disease. BMC Neurosci 2004, 5:14

29. Petrucelli L, O'Farrell C, Lockhart PJ, Baptista M, Kehoe K, Vink L, Choi P Wolozin B, Farrer M, Hardy J, et al: Parkin protects against the toxicity associated with mutant alpha-synuclein: proteasome dysfunction selectively affects catecholaminergic neurons. Neuron 2002, 36(6):1007-1019.

30. Yang Y, Nishimura I, Imai Y, Takahashi R, Lu B: Parkin suppresses dopaminergic neuron-selective neurotoxicity induced by Pael- $R$ in Drosophila. Neuron 2003, 37(6):911-924

31. von Coelln R, Thomas B, Andrabi SA, Lim KL, Savitt JM, Saffary R, Stirling W, Bruno K, Hess EJ, Lee MK, et al: Inclusion body formation and neurodegeneration are parkin-independent in a mouse model of alphasynucleinopathy. J Neurosci 2006, 26(14):3685-3696.

32. Kahle PJ, Neumann M, Ozmen L, Muller V, Odoy S, Okamoto N, Jacobsen H, Iwatsubo T, Trojanowski JQ, Takahashi H, et al: Selective insolubility of alpha-synuclein in human Lewy body diseases is recapitulated in a transgenic mouse model. Am J Pathol 2001, 159(6):2215-2225.

33. Itier JM, Ibanez P, Mena MA, Abbas N, Cohen-Salmon C, Bohme GA, Laville M, Pratt $J$, Corti O, Pradier L, et al: Parkin gene inactivation alters behaviour and dopamine neurotransmission in the mouse. Hum Mol Genet 2003, 12(18):2277-2291.

34. Vitte J, Traver S, Maues De Paula A, Lesage S, Rovelli G, Corti O, Duyckaerts C, Brice A: Leucine-rich repeat kinase 2 is associated with the endoplasmic reticulum in dopaminergic neurons and accumulates in the core of Lewy bodies in Parkinson disease. J Neuropathol Exp Neurol 2010, 69(9):959-972

35. Jan C, Muriel MP, Rolland AS, Hirsch EC, Francois C: Localization of D1a dopamine receptors on cell bodies and axonal endings in the substantia nigra pars reticulata of the rat. J Neural Transm 2007, 114(12):1509-1517.

36. Thingholm TE, Larsen MR: The use of titanium dioxide micro-columns to selectively isolate phosphopeptides from proteolytic digests. Methods Mol Biol 2009, 527:57-66. xi.

37. Mbefo MK, Paleologou KE, Boucharaba A, Oueslati A, Schell H, Fournier M, Olschewski D, Yin G, Zweckstetter M, Masliah E, et al: Phosphorylation of synucleins by members of the Polo-like kinase family. J Biol Chem 2010, 285(4):2807-2822.

38. Paleologou KE, Schmid AW, Rospigliosi CC, Kim HY, Lamberto GR, Fredenburg RA, Lansbury PT Jr, Fernandez CO, Eliezer D, Zweckstetter M, et al: Phosphorylation at Ser-129 but not the phosphomimics S129E/D inhibits the fibrillation of alpha-synuclein. J Biol Chem 2008, 283(24):16895-16905.

39. Inglis KJ, Chereau D, Brigham EF, Chiou SS, Schobel S, Frigon NL, Yu M, Caccavello RJ, Nelson S, Motter R, et al: Polo-like kinase 2 (PLK2) phosphorylates alpha-synuclein at serine 129 in central nervous system. J Biol Chem 2009, 284(5):2598-2602.

40. Stefanis L, Larsen KE, Rideout HJ, Sulzer D, Greene LA: Expression of A53T mutant but not wild-type alpha-synuclein in PC12 cells induces alterations of the ubiquitin-dependent degradation system, loss of dopamine release, and autophagic cell death. J Neurosci 2001, 21(24):9549-9560.

41. Tanaka Y, Engelender S, Igarashi S, Rao RK, Wanner T, Tanzi RE, Sawa A, LD $V$, Dawson TM, Ross CA: Inducible expression of mutant alpha-synuclein decreases proteasome activity and increases sensitivity to mitochondriadependent apoptosis. Hum Mol Genet 2001, 10(9):919-926.

42. Lewis KA, Yaeger A, DeMartino GN, Thomas PJ: Accelerated formation of alpha-synuclein oligomers by concerted action of the $20 \mathrm{~S}$ proteasome and familial Parkinson mutations. J Bioenerg Biomembr 2010, 42(1):85-95.

43. Choubey V, Safiulina D, Vaarmann A, Cagalinec M, Wareski P, Kuum M, Zharkovsky A, Kaasik A: Mutant A53T alpha-synuclein induces neuronal death by increasing mitochondrial autophagy. J Biol Chem 2011, 286(12):10814-10824.

doi:10.1186/1471-2202-14-135

Cite this article as: Fournier et al.: Parkin depletion delays motor decline dose-dependently without overtly affecting neuropathology in a-synuclein transgenic mice. BMC Neuroscience 2013 14:135. 